\title{
PROJETO AMORA: CAPACITANDO MULHERES EM DIREITOS HUMANOS E CIDADANIA
}

\author{
MULBERRY PROJECT: EMPOWERING WOMEN IN HUMAN RIGHTS AND \\ CITIZENSHIP \\ Juliana Alice Fernandes Gonçalves ${ }^{1}$ \\ Maiara Leandro ${ }^{2}$ \\ Mauricio da Cunha Savino Filó ${ }^{3}$ \\ Monica Ovinski de Camargo Cortina ${ }^{4}$
}

\begin{abstract}
RESUMO
O Projeto Amora tem como objetivo capacitar mulheres em situação de vulnerabilidade social em direitos humanos e promover a cidadania. Está em seu quinto ano de atuação e é direcionado atualmente às mulheres beneficiárias de programas sociais de transferência de renda, que são assistidas pelos CRAS de Criciúma-SC. Orienta-se pela concepção de extensão que pretende produzir conhecimento por meio do diálogo direto com a comunidade. Os resultados obtidos apontam para a importância de ações de extensão voltadas ao estímulo da cidadania e ao protagonismo das mulheres no contexto atual.

Palavras-chave: Mulheres; Direitos Humanos; Cidadania; Extensão.
\end{abstract}

\begin{abstract}
Mulberry Project aims to offer training course to women in vulnerable social situation in human rights and promote citizenship. Is in its fifth year of operation and is currently directed to female beneficiaries of social cash transfer programs, which are supported by CRAS Criciuma -SC. Guides for the design of extension you want to produce knowledge through direct dialogue with the community. Promotes women's knowledge about human rights of women in the following areas: gender, diversity, sexual and reproductive rights, violence against women and political participation. Employs active methodologies of knowledge through dynamic, drawings, renderings, music, videos and dialogues. The results point to the importance of extension of actions aimed at stimulating citizenship and the role of women in the current context.

Keywords: Women; Humans Rights; Citizenship; Extension.
\end{abstract}

\footnotetext{
${ }^{1}$ Graduanda em Direito - Unesc / Criciúma-SC.

${ }^{2}$ Graduanda em Psicologia - Unesc / Criciúma-SC.

${ }^{3}$ Doutorando em Direito - PPGD/UFSC / Florianópolis-SC.

${ }^{4}$ Mestre em Direito - PPGD/UFSC / Florianópolis-SC.
} 


\section{INTRODUÇÃO}

Os direitos humanos das mulheres constituem um catálogo recente de direitos, produzidos por meio da atuação direta dos movimentos sociais e elaborados a partir das demandas das mulheres do mundo todo. Tal catálogo está em permanente construção e, para se legitimar, pretende uma construção local, que parta das comunidades e que se fundamente no reconhecimento da diferença como passo necessário para se alçar a igualdade. Superando a visão de uma mulher universal, os direitos humanos das mulheres são concebidos como um mosaico em permanente composição, que inclua a diversidade, atendendo as especificidades dos grupos distintos de mulheres.

Nesse sentido, a extensão universitária se apresenta como importante mecanismo de produção de conhecimento, de intercâmbio de ideias entre a academia e a comunidade, vistas não como locus separados, mas como partes de um todo, que precisam interagir para transformar a realidade. O Projeto Amora se constitui dentro dessa proposta, como extensão universitária que pretende intervir na realidade e produzir conhecimento, enquanto instrumento de construção dos direitos humanos das mulheres e para as mulheres. Reunindo partes do mosaico de mulheres que compõem as comunidades assistidas pelo projeto, o Projeto Amora é uma iniciativa interdisciplinar que promove a cidadania de mulheres beneficiárias de programas socioassistenciais do Estado, assistidas pelos CRAS de Criciúma$\mathrm{SC}$, com o qual forma uma parceria bem sucedida.

Esse artigo tem como objetivo apresentar o Projeto Amora enquanto projeto de extensão universitária, esclarecer os princípios que orientam sua atividade e analisar os resultados obtidos em sua atuação, assistindo mais de 200 (duzentas) mulheres no último ano. Para tanto, inicialmente examinar-se-á os princípios, conceitos e categorias teóricas que fundamentam sua atuação. Em seguida, cumpre apresentar o projeto, seu histórico, suas metodologias e os resultados alcançados. Finalmente, importa refletir sobre os resultados e avaliar a importância dessa atividade de extensão para a formação acadêmica, para a construção do conhecimento e para a transformação da comunidade onde atua.

\section{GÊNERO E DIREITOS HUMANOS DAS MULHERES: A EXTENSÃO UNIVERSITÁRIA COMO INSTRUMENTO DE CIDADANIA}

Inicialmente, antes de expor o conhecimento produzido pelas atividades de extensão, cumpre elucidar alguns conceitos que nortearam as práticas desenvolvidas. Esta revisão teórica consiste na verificação da importância da extensão universitária bem como do modelo de projeto desenvolvido, de acordo com as temáticas propostas ao público alvo: as mulheres. 
Nesse sentido, é relevante expor a concepção de extensão universitária e destacar o seu papel para todos os envolvidos: universidade, docentes, discentes e, sobretudo, a comunidade. Por conseguinte, como o projeto de extensão em tela realiza uma capacitação sobre direitos humanos das mulheres, explanar-se-á sobre os conteúdos que são ofertados durante as capacitações, sendo eles: mulheres e gênero, respeitando a diversidade, direitos sexuais e reprodutivos e saúde das mulheres, violência contra as mulheres, formas de prevenção e enfrentamento da violência contra as mulheres, e cidadania e participação feminina em espaços públicos. Isso porque se acredita que a abrangência desse conjunto atinge de forma mais direta o objetivo de despertar a autonomia e o reconhecimento de sua pertença enquanto mulheres.

A universidade é um espaço de produção e disseminação de conhecimento, onde se fomenta um ambiente propício para o pensar e o criar. É na universidade que são formados cidadãos e cidadãs mais conscientes de seu papel social enquanto profissionais para o mercado de trabalho, e justamente, nesta perspectiva, é que se deve pensar nos objetivos básicos deste ambiente plural, que é a academia. "Neste contexto está a extensão universitária, apresenta uma diversidade conceitual e prática que interfere expressivamente no 'pensar' e no 'fazer' no interior da Universidade" (SERRANO, 2015).

Interessante compreender que a universidade, enquanto instituição de expressão para a sociedade, deve fazer jus ao seu significado, ou seja, além de produzir o saber em si, deve transpor os limites de seus muros e suas salas, buscando a comunidade de modo a aprender com seus saberes. Portanto, a educação, enquanto prática libertadora, é estabelecida enquanto diálogo, como troca de saberes entre a comunidade e a academia, para produzir um novo conhecimento. Pois, de que adianta o conhecimento se ele não for produzido de forma compartilhada? Está é uma compreensão freiriana que pode, e deve, ser adotada como ponto de partida:

\footnotetext{
Educar e educar-se, na prática da liberdade, não é estender algo desde a "sede do saber", até a "sede da ignorância" para "salvar", com este saber, os que habitam nesta. Ao contrário, educar e educar-se, na prática da liberdade é tarefa daqueles que sabem que pouco sabem - por isto sabem que sabem algo e podem assim chegar a saber mais - em diálogo com aqueles que, quase sempre, pensam que nada sabem, para que estes, transformando seu pensar que nada sabem em saber que pouco sabem, possam igualmente saber mais" (FREIRE, 2006, p. 25).
}

No Brasil, a extensão universitária transitou por diversas conceituações e matizes, "da extensão cursos, à extensão serviço, à extensão assistencial, à extensão 'redentora da função social da Universidade', à extensão como mão dupla entre universidade e sociedade, à extensão cidadã” (SERRANO, 2015), e neste contexto se verifica uma ressignificação da 
extensão nas relações internas com os outros fazeres acadêmicos, ou seja, como meio de transformação social e educacional, pois através dela não só a comunidade que adquire conhecimento, como os próprios envolvidos, sejam professores orientadores ou acadêmicos, pois a vivência das pessoas é tão ou mais importante do que o aprendido em sala de aula.

Segundo Gurgel (1986), existem princípios que alimentam a extensão e eles se dividem em seis. O princípio da retroalimentação, que representa a via de mão dupla, ou seja, duas direções que trabalham juntas e possibilita mudanças nos dois sentidos. A integração, onde a unificação de subsistemas configuram em uma articulação de melhoria. A "abertura ao meio, no sentido de cumprimento de uma missão social”. O princípio do equilíbrio com as demais funções do meio acadêmico, que forma e transforma futuras posturas profissionais positivamente. "Mentalização, no sentido de uma atuação participativa da universidade. Projeção, da instituição de ensino como uma totalidade, participando de um processo maior de transformação" (GURGEL, 1986, p. 161).

O Projeto Amora foi construído e vem sendo aplicado sob a "[...] ideia de uma extensão a serviço de um processo transformador, emancipatório e democrático; e ainda, de uma extensão desenvolvida no diálogo e no respeito a cultura local" (SERRANO, 2015), nos moldes do pensamento freiriano. Nesta perspectiva, se refletiu sobre a necessidade de um projeto voltado às mulheres da comunidade de Criciúma-SC, e após algumas modificações, delimitou-se ainda mais o público-alvo, e assim, a partir do ano de 2014, as capacitações foram ofertadas às mulheres beneficiárias do Programa Bolsa Família ${ }^{5}$, assistidas pelos CRAS (Centro de Referência em Assistência Social) ${ }^{6}$ de Criciúma/SC, e, no ano de 2015, foi estendido às mulheres beneficiárias do Programa Renda Mínima, também assistidas pelos CRAS.

Mas por que um projeto voltado para as mulheres? Sob que fundamentos e quais os reais objetivos? As mulheres formam um grupo social que estão em desigualdade social em relação aos homens, o que pode ser constatado atualmente nos dados sobre a violência contra as mulheres e sobre as diferenças salariais no mercado de trabalho, senão veja-se a seguir. No

\footnotetext{
${ }^{5}$ O Programa Bolsa Família (PBF) foi estabelecido pela Lei n. 10.836/2004 e pelo Decreto n. 5.309/2004 e consiste em um "[...] programa de transferência direta de renda que beneficia famílias em situação de pobreza e de extrema pobreza em todo o país. O Bolsa Família integra o Plano Brasil Sem Miséria, que tem como foco de atuação os milhões de brasileiros com renda familiar per capita inferior a R\$ 77 mensais e está baseado na garantia de renda, inclusão produtiva e no acesso aos serviços públicos” (BRASIL, 2015b).

6 “O CRAS - Centro de Referência da Assistência Social é uma unidade pública estatal localizada em áreas com maiores índices de vulnerabilidade e risco social, destinada ao atendimento socioassitencial de famílias" (BRASIL, 2015a).
} 
mercado de trabalho, conforme dados do RAIS ${ }^{7}$ sobre Santa Catarina, “o percentual do rendimento feminino em relação ao masculino era de 78,9\% em 2013, independentemente da escolaridade. Entre os de nível superior, a desigualdade salarial aumenta: o percentual passa para 65,6\%" (ODM, 2015). Em relação à violência contra as mulheres, os dados do município são significativos. Conforme o ranking da taxa de homicídios ${ }^{8}$ femininos no Brasil, registrado no Mapa da Violência de 2012, Criciúma é o $3^{\circ}$ município do Estado de Santa Catarina com maior taxa de homicídio de mulheres (perde apenas para Lages e Mafra) e está na lista dos 100 municípios com mais homicídios de mulheres do Brasil, ocupando a 83a colocação (WAISELFISZ, 2012, p. 14-15).

As mulheres, durante a história ocidental recente, tiveram de trilhar um caminho árduo para alcançar o que se tem hoje, e mesmo diante de atuações de movimentos feministas e a consequente efetivação de alguns direitos, ainda não se atingiu equidade idealizada. Para Joan Scott (2005, p. 15), “a igualdade é um princípio absoluto e uma prática historicamente contingente", pois não se trata de ausência ou eliminação da diferença, mas sim da decisão de ignorá-la ou levá-la em consideração.

As relações sociais assimétricas, que colocam as mulheres em situação de desvantagem, são oriundas de uma transformação social secular onde o interesse pessoal das mulheres foi dissuadido em favor e em vontade dos homens. Sua atuação não é para si, mas para outrem, se sujeitando ao que dita a sociedade. Trata-se de um conjunto de dominação ditatorial de regras em favor dos homens e em desfavor das mulheres (DIMEN, 1997, p. 46).

Nos últimos anos buscou-se, através de pesquisas acadêmicas, bem como por movimentos sociais, consolidar as teorias feministas para examinar o sistema imposto, pois este domínio sobre as mulheres possui várias vertentes como fundamentação, seja pelo viés econômico ou social, e anseia-se explicar porque o sistema de poder funciona de tal modo (SCOTT, 1989, p. 10).

Diante de tal cenário, cabe aqui deslindar a expressão "igualdade de gênero" anteriormente citada, considerando que a categoria de gênero passou a ser mais utilizada pelas feministas para se referir à organização social da relação entre os sexos, no sentido mais literal. No seu uso mais recente e simples, a palavra "gênero" é sinônimo de "mulheres", justamente porque a primeira expressão conota mais objetividade e seriedade ao tema e

\footnotetext{
7 A Relação Anual de Informações Sociais - RAIS - coleta os dados estatísticos e apresenta sua análise principalmente sobre a temática do trabalho.

${ }^{8}$ A taxa é calculada através do número de homicídio praticados para cada 100.000 habitantes. Esta taxa é o mais importante indicador de segurança pública de uma região, porque trata de um crime com boa margem de notificação (baixa cifra oculta) e que leva em consideração a população residente no mesmo território.
} 
passou a adquirir legitimidade acadêmica por volta dos anos 1980. Segundo Joan Scott (1989, p. 7), a questão do gênero sugere que "a informação a respeito das mulheres é necessariamente informação sobre os homens, que um implica no estudo do outro", o uso deste termo se refere a domínios "tanto estruturais quanto ideológicos - que implicam em relações entre sexos".

Diante do explicitado se verifica que há sim uma maior vulnerabilidade por parte das mulheres, por uma trajetória histórica que resulta nas situações sociais, econômicas e culturais vigentes, e que estas distinções devem ser levadas em consideração, para que tratando de forma desigual os seres desiguais se chegue à igualdade ${ }^{9}$. Pensando nesta realidade, o Projeto Amora foi construído na perspectiva plural, de forma interdisciplinar, onde as mulheres assistidas serão capacitadas sobre os instrumentos de proteção e defesa dos seus direitos e poderão ser multiplicadoras desse conhecimento junto à sua comunidade e família.

Para melhor desenvolver as atividades de extensão, foram realizadas leituras dentro da perspectiva de direitos humanos das mulheres, sobre a problemática de gênero, diversidade sob a ênfase da diferença entre preconceito e discriminação, bem como sobre a saúde da mulher e, ainda, sua participação em espaços públicos, e, sobretudo, a respeito da violência de gênero. Alinhando a compreensão teórica às práticas extensionistas, percebe-se que o públicoalvo que é conduzido pelo projeto é o mais vulnerável dentro de um cenário subdividido, pois são inúmeros os fatores que as colocam no seio mais periférico da sociedade. São mulheres, pobres, em sua maioria negras ou pardas, mães jovens com um número elevado de filhos, no mais das vezes solteiras, também composto pelas mais idosas (avós), residentes em locais com alta taxa de criminalidade ou de visibilidade negativa por parte da sociedade, ou seja, um conjunto de características que as desfavorecem no contexto social.

É a partir deste cenário que se verifica a importância da inserção do projeto e de suas temáticas na comunidade para estas mulheres, pois estas que mais necessitam de informações sobre seus direitos, são as que menos usufruem delas. Incorporado a isto, interessante elencar, de forma concisa, conceituações trabalhadas e repassadas a estes grupos.

Inicialmente, os Direitos Humanos, que possui como fundamento o princípio de dignidade inerente à condição humana, e mais propriamente os Direitos Humanos das Mulheres, que merecem tal distinção, pelas violações específicas que sofrem continuamente, pois de acordo com Azambuja e Nogueira (2015):

\footnotetext{
${ }^{9}$ SANTOS, Boaventura de Souza. "Temos o direito a ser iguais quando a nossa diferença nos inferioriza; e temos o direito a ser diferentes quando nossa igualdade nos descaracteriza. Daí a necessidade de uma igualdade que reconheça as diferenças e de uma diferença que não produza, alimente ou reproduza as desigualdades”.
} 
[...] a maior parte dos pobres do mundo são mulheres; a maior parte dos analfabetos são mulheres; a maior parte dos crimes sexuais são praticados contra mulheres; as mulheres e jovens são a maior parte da pessoas traficadas e exploradas sexualmente; quem mais sofre as conseqüências da falta de assistência e de cuidado na saúde sexual e reprodutiva são as mulheres e as adolescentes e, por fim, a maior parte dos refugiados e deslocados em situações de guerra e conflitos armados, externos e internos, são as mulheres e suas crianças.

Ou seja, os direitos humanos das mulheres estão em permanente construção, com o intuito de dirimir injustiças sociais, econômicas, culturais etc., contra as mulheres, "se apresentando como um espaço constante de luta, em que a ação dos movimentos de mulheres tem sido fundamental para o seu questionamento e análise crítica" (AZAMBUJA; NOGUEIRA, 2015).

Alinhada a essa perspectiva, como anteriormente citado, o público assistido no Projeto Amora é o que possui atenção e tratamento mais precários da sociedade, ou seja, alvos cotidianos de preconceito e discriminação. São consideradas como seres desiguais e sofrem com a máxima desta violação. De acordo com Raupp Rios (2002, p. 53), “a arbitrariedade do tratamento desigual aparece como condição necessária e suficiente para a violação da máxima da igualdade".

No campo da saúde pública, há também o problema da violência praticada contra as mulheres, mas salienta-se que transformações concernentes ao tema vêm sendo mais efetivas, e que uma maior atenção foi dada a tratamentos hospitalares em caso de violência doméstica (AZAMBUJA; NOGUEIRA, 2015). Ocorre que uma das principais reclamações das mulheres assistidas pelo projeto gira em torno dos direitos reprodutivos e da saúde feminina, sendo altos os índices de reclamações sobre violência obstétrica.

Quanto à cidadania feminina e a participação da mulher em espaços públicos, pode-se dizer que poucos contextos realçaram os resultados das lutas concernentes, "como os de criação de instrumentos de proteção aos direitos humanos, que resultaram na incorporação das questões da mulher a uma agenda social internacional" (PRÁ; EPPING, 2015), e garantem ainda as autoras que "o aparente reconhecimento da cidadania feminina e a sua inclusão em programas de governos e em agendas nacionais [...] não têm se mostrado capaz de garantir todos os direitos humanos a todas as mulheres" e que, portanto, "essa tarefa continua imperativa para quem defende a expansão da cidadania feminina e a equidade de gênero" (PRÁ; EPPING, 2015).

Por fim, a questão da violência doméstica/de gênero, que é muito mais presente do que se imagina. $\mathrm{O}$ fato de ser mulher é um fator de risco para ser vítima de violência doméstica ou familiar, já que as mulheres têm maior probabilidade de serem machucadas, estupradas por companheiros ou estranhos (CANTERA, 2007, p. 41-42). Diversas pesquisas acadêmicas, 
bem como realizadas por órgãos e organizações nacionais e internacionais, demonstram a perpetuação da violência contra a mulher. Estudos da Organização Mundial da Saúde (OMS) "indicam que quase metade das mulheres vítimas de homicídio são assassinadas pelo marido ou namorado, ex ou atual” (SABADELL, 2008, p. 258). Dados coletados pela Anistia Internacional em cinquenta países revelam que "uma em casa três mulheres foi vítima de violência doméstica, foi obrigada a manter relações sexuais ou submetida a outros tipos de violência (2008, p. 258). Em 2005 a OMS “elaborou um estudo sobre a saúde da mulher e a violência doméstica em dez países, incluindo o Brasil, e constatou que, apesar dos compromissos internacionais assumidos, não ocorreram mudanças significativas no que se refere à prática deste tipo de violência" (SABADELL, 2008, p. 259).

A violência que vitimiza as mulheres, na maioria dos casos, é perpetrada por homens conhecidos e dentro do ambiente doméstico. Esse padrão de violência se perpetua e deve ser rompido: "Em tempos de mudança, essa forma de ver as coisas funciona como um obstáculo epistemológico e como uma barreira ideológica que impedem de pensar, ver e desejar as coisas do outro modo" (CANTERA, 2007, p. 45). Destarte, questões em torno da cultura da violência de gênero se reproduzem sob o manto da naturalização, que impede sua visibilidade e, consequentemente, a reflexão sobre a mudança de atitude. E é justamente por circunstâncias como estas que o Projeto Amora se justifica e pauta sua atuação, pois leva informações necessárias para que estas mulheres possam suscitar demandas e lutar pela efetivação de seus direitos.

Diante de todo o explanado, observa-se que as formas de violência contra as mulheres são legitimadas por aspectos culturais e sociais que atravessam um longo período histórico, pela permanência de uma estrutura social desigual. Através desta realidade se percebe a urgência de ações educativas e de diálogo que promovam a cidadania para as mulheres, para que se alcance uma condição real de respeito e alteridade, que são necessários para um equilíbrio coletivo.

\section{O PROJETO AMORA: CAPACITANDO MULHERES E FOMENTANDO A CIDADANIA}

Feitas as considerações teóricas para elucidar os princípios que orientam e justificam o Projeto Amora, cuida-se a seguir de apresentar o projeto, sua metodologia de trabalho e examinar os resultados alcançados por sua atuação.

O Projeto Amora tem uma história que o consolida como projeto de extensão e está no seu quinto ano de atuação, sob o financiamento obtido sucessivamente nos Editais de 
Extensão da UNACSA/UNESC ${ }^{10}$. O Amora representa a continuidade de um projeto de extensão criado em 2011, intitulado "Mulheres e cidadania: costurando conhecimentos sobre a Lei Maria da Penha (Lei 11.340/2006)". Inicialmente o projeto atuava em Grupos de Inclusão Produtiva, chamados de Clube de Mães, e seu objetivo era difundir os instrumentos jurídicos previstos na Lei Maria da Penha, com a desnaturalização das formas de violência contra as mulheres, através de palestras e dinâmicas de grupo. Nos anos de 2011 e 2012 o projeto atuou com parceria da AFASC (Associação Feminina de Assistência Social) de Criciúma e assistiu mulheres participantes de 64 Grupos de Inclusão Produtiva. Em 2013 o projeto foi replicado em Içara-SC, em parceria com a FAI (Fundação de Assistência Social), e atuou em 38 Clubes de Mães do município, incluindo a capacitação de mulheres residentes em áreas urbanas e rurais. No final de 2013, após promover o projeto nas 6 (seis) unidades dos CRAS de Criciúma-SC e perceber ali a demanda de um conhecimento mais amplo entre as mulheres assistidas, a equipe de extensionistas reinventou o projeto e estruturou uma capacitação em Direitos Humanos das Mulheres mais aprofundada, dividida em 6 (seis) módulos, abrangendo temas diversos e correlacionados à violência, o que demandava também a modificação da metodologia de atuação. Então, através de estudos realizados, destacou-se pesquisas que comprovam que o município de Criciúma é o terceiro do estado com maior taxa de feminicídios e que está no ranking das cem cidades no Brasil, ocupando o octogésimo terceiro lugar. Neste novo modelo, o projeto voltou-se para a capacitação de mulheres beneficiárias do Programa Bolsa Família, assistidas pelos CRAS do município de Criciúma, e não seriam mais palestras únicas e sim capacitações, incluindo temas relativos aos direitos sexuais e reprodutivos, gênero, prevenção da violência e participação cidadã. Dada a nova etapa das ações extensionistas e diante da necessidade de um nome mais curto e fácil de ser memorizado, surge o novo nome do projeto: Amora. Nome escolhido pelas características da própria fruta, a qual possui gomos de diferentes tamanhos, que representam a diversidade das mulheres assistidas pelo projeto. Estes gomos se agrupam para se prender ao caule e, nesse sentido, o projeto pretende reunir as mulheres em torno do propósito comum do conhecimento de direitos específicos para atender as demandas das mulheres e também pela ciência de seus deveres, pela necessidade da participação cidadã nos espaços públicos de discussão e efetivação de seus direitos (CORTINA, 2006, p. 1-4).

Para um melhor alcance nos objetivos, seis módulos foram elaborados para a capacitação ofertada pelo projeto, com os seguintes temas: "Mulheres e Gênero", no qual são

\footnotetext{
${ }^{10}$ Unidade de Ciências Sociais Aplicadas da Universidade do Extremo Sul Catarinense.
} 
difundidos os valores da autoestima das mulheres, identidade, gênero, papeis sociais e mulheres como sujeitos de direito; "Respeitando a Diversidade", que tem o intuito de discutir as diferenças entre as pessoas e incentivar o conviver sadio, apresentando os prejuízos causados pelos preconceitos, discriminações e marcadores sociais; "Direitos sexuais, reprodutivos e saúde das mulheres”, que aborda o direito à autonomia, corpo, sexualidade, maternidade e saúde da mulher; "Violência contra as mulheres", que introduz o tema da violência doméstica e familiar, ressaltando os tipos de violência, a importância da denúncia, as formas de prevenção e enfrentamento da violência contra as mulheres; e por fim, “Cidadania e participação feminina em espaços públicos”, apresenta conteúdos que estimulam as formas de participação comunitária e vivência democrática, caracterizando a importância da representatividade das mulheres (CORTINA, 2006, p. 7-8).

Estes temas são apresentados em módulos para os grupos de mulheres das 6 (seis) unidades dos CRAS de Criciúma, com frequência mensal, totalizando seis módulos com duração de seis meses (CORTINA, 2006, p. 8-9).

A metodologia para aplicação dos módulos tem como prioridade envolver as mulheres através de atividades lúdicas, trabalhar com linguagem acessível e dinamizar os debates através de vídeos e slides interativos (CORTINA, 2006, p. 8-9).

O projeto é composto por dois professores coordenadores e duas bolsistas, sendo uma do Curso de Direito e outra do Curso de Psicologia, visto que os temas possuem abordagem interdisciplinar. A professora e o professor acompanham as bolsistas em todas as fases do projeto. A primeira etapa das atividades, em 2014, consistiu na orientação de leituras relacionadas ao tema, debates e esclarecimento de dúvidas. Para conhecimento in loco dos temas estudados, foram realizadas visitas à "Delegacia de Polícia da Criança, Adolescentes e Proteção a Mulher e Idoso", ao Instituto Médico Legal (IML) e as seis unidades dos CRAS, todos situados no município de Criciúma. Na segunda etapa, a equipe elaborou os módulos, prevendo todas as atividades que seriam desenvolvidas e as técnicas metodológicas empregadas. Em sequência, as bolsistas conduziram as aplicações dos conteúdos dos módulos para as mulheres assistidas, tendo por vezes o acompanhamento dos professores orientadores.

O projeto pretende capacitar mulheres sobre os instrumentos de proteção e defesa dos seus direitos. Observa-se que este projeto adota a educação como instrumento de cidadania e prevenção da violência, ao partilhar experiências e construir conhecimentos novos e diferenciados sobre os direitos, pois atua junto às distintas realidades de cada território do município. Em cada grupo de mulheres emergem novos conhecimentos e aplicações para os 
direitos previstos em leis, o que demonstra que a cidadania é um processo que está em permanente construção (CORTINA, 2006, p. 13).

\section{RESULTADOS OBTIDOS E REFLEXÕES NECESSÁRIAS: EXTENSÃO ACADÊMICA COMO INSTRUMENTO DE PRODUÇÃO DE CONHECIMENTO}

Houve uma grande adesão das mulheres assistidas ao Projeto Amora, visível pelo grau de interação entre elas e com a equipe do projeto, ao realizar as propostas de atividades e debater os temas. A interação das mulheres foi crescente no decorrer dos módulos, na medida em que eram fortalecidos os vínculos do grupo. Este foi, sem dúvida, um dos méritos obtidos pelas extensionistas, pois para tratar certos temas era necessária uma intimidade com as mulheres, para que os objetivos fossem alcançados.

Ao abordar o tema de violência foi possível detectar uma aparente "normalidade" sobre o assunto, retratando que esta vivência constitui parte da realidade dessas mulheres. Todavia, nos encontros emergiram relatos de mulheres que passaram por alguma situação de violência e que os superaram. Estes relatos contribuíram para a construção de conhecimentos e vivências de alto valor, pois não se constituíam em meros argumentos, mas em testemunhos que fortaleciam a esperança para as mulheres que talvez vivenciavam idênticos problemas, mas em silêncio. Dessa forma, foram construídos coletivamente os instrumentos para incentivar a denúncia e o consequente rompimento do ciclo da violência.

Outro ponto perceptível foram os relatos de situações de discriminação social e racial, vivenciadas pelas mulheres, por seus filhos (as) ou companheiros, devido aos locais onde residem, em bairros afastados de periferia, caracterizados por apresentar registros policiais e por ser residência de pessoas de baixa renda, ou ainda, a identificação de pertença a grupos étnicos raciais discriminados no município. Os relatos destas situações foram narrados com certo tipo de sofrimento, pois estão associados ao prejuízo na busca por empregos, ao tratamento recebido em um simples passeio no shopping center e na própria educação aos filhos.

No que tange ao tema da saúde da mulher, muitos foram os relatos de mau atendimento junto à rede do Sistema Único de Saúde, com falta de humanização e desprezo durante o parto, exames ginecológicos e no trato com os filhos. Isso implica na necessidade de atenção e melhorias no SUS, para que possa prestar melhor atendimento e superar as formas de violência no trato com mulheres no momento do parto ou após o parto.

No último módulo, que aborda o assunto da cidadania, algumas mulheres compartilharam ideias de participação política. Sendo isso uma grande vitória do projeto, pois 
muitas relataram seus projetos pessoais de participação, sonhos futuros, obtendo do grupo e das extensionistas o estímulo necessário para que tenham força de vontade para realizá-los.

Por fim, observa-se que, ao participar das práticas extensionistas, as acadêmicas tiveram o privilégio de adquirir não só uma grande experiência, mas de conhecer a realidade de seu município, modificar suas visões sociais e, acima de tudo, tornar-se profissionais mais preparadas para atuar junto às comunidades e ingressar no mercado de trabalho mais conscientes de seu papel social.

\section{CONCLUSÃO}

Por todo o exposto neste artigo extensionista, pôde-se chegar a algumas conclusões e verificações, que podem servir de aporte para novas pesquisas e extensão.

Em primeiro lugar, verificou-se uma população feminina vulnerável, dependente e carente de recursos e informações básicas, estando - em grande parte - à margem de qualquer atividade que lhe permitam uma inserção para sair dessa vulnerabilidade. Ao mesmo tempo, percebe-se que essa realidade que atinge inúmeras mulheres é, ao mesmo tempo, promovida e perpetuada pelo sistema social/cultural e por membros de suas próprias famílias.

O conhecimento produzido através do diálogo e da interação com a realidade se mostrou muito profícuo. Destarte, o objetivo é produzir conhecimento e autonomia das mulheres assistidas pelo projeto, para que não seja gerada uma dependência do projeto, mas que as ações propostas sejam vistas como uma oportunidade importante para as trocas e para resultar em conhecimento mútuo.

Neste sentido caminhou o Projeto Amora, que por meio de seis encontros com cada grupo de mulheres, conseguiu verificar uma realidade nem sempre ouvida, dentro ou fora de seus lares, e promoveu um grande intercâmbio de ideias entre as participantes, a fim de que elas pudessem se tornar conscientes de que devem ser protagonistas de suas próprias vidas.

Por se tratar de um projeto de extensão, que não pode se propor a substituir a atuação do Estado por meio de seus necessários serviços públicos, a estratégia adotada foi a de que elas se tornassem mais conscientes de seus direitos enquanto cidadãs e enquanto finalidade dos serviços públicos, notadamente o serviço público de saúde, no momento da gestação até o pós parto.

Na vida familiar, o combate à violência doméstica encontrou melhor aplicação quando foram realizados trabalhos conjuntos, por meio de falas, representações, cartazes, diálogos, músicas e vídeos. Outrossim, foi-lhes repassada a importância de serem também disseminadoras do conhecimento produzido na comunidade e na família nas quais convivem. 
Por fim, os resultados do projeto apontam para seu relevante interesse social, pois atinge a uma parcela importante, mas esquecida, da população criciumense, que precisa de ouvidos e de vozes para alcançar a plena cidadania.

\section{REFERÊNCIAS}

AZAMBUJA, Mariana Porto Ruwer de; NOGUEIRA, Conceição. Introdução à violência contra as mulheres como um problema de direitos humanos e de saúde pública. Disponível em: $\quad<$ http://www.scielo.br/scielo.php?script=sci_arttext\&pid=S0104-

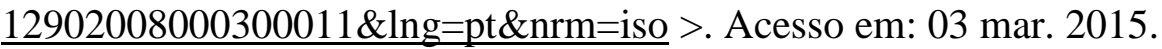

BRASIL. Ministério de Desenvolvimento Social (MDS). CRAS Institucional. Disponível em: <http://www.mds.gov.br/falemds/perguntas-frequentes/assistencia-social/psbprotecao-especial-basica/cras-centro-de-referencias-de-assistencia-social/crasinstitucional>. Acesso em: 12 abr. 2015a.

BRASIL. Ministério de Desenvolvimento Social (MDS). Programa Bolsa Família. Disponível em: < http://www.mds.gov.br/bolsafamilia>. Acesso em: 12 abr. 2015 b.

CANTERA, Leonor M. Casais e violência: um enfoque além do gênero. Porto Alegre: Dom Quixote, 2007.

CORTINA, Monica Ovinski de Camargo. Projeto de extensão. Criciúma, SC: UNESC, 2014. Mimeo.

PRA, Jussara Reis; EPPING, Léa. Cidadania e feminismo no reconhecimento dos direitos humanos das mulheres. Rev. Estud. Fem., Florianópolis, v. 20, n. 1, abr. 2012. Disponível em: <http://www.scielo.br/scielo.php?script=sci_arttext\&pid=S0104026X2012000100003\&lng=pt\&nrm=iso>. Acesso em: 12 abr. 2015.

FREIRE, Paulo. Extensão ou Comunicação. 13 Ed. São Paulo: Paz e Terra. 2006.

GURGEL, Roberto Mauro. Extensão universitária: comunicação ou domesticação. São Paulo: Cortez, 1986.

ODM. Objetivos do Milênio. Relatórios dinâmicos. Disponível em: $<$ http://www.relatoriosdinamicos.com.br/portalodm/3-igualdade-entre-sexos-evalorizacao-da-mulher/BRA004042/santa-catarina>. Acesso em: 12 abr. 2015.

RIOS, Roger Raupp. O princípio da igualdade e a discriminação por orientação sexual: a homossexualidade no direito brasileiro e norte-americano. São Paulo: Revista dos Tribunais, 2002.

SABADELL, Ana Lucia. Manual de sociologia jurídica: introdução a uma leitura externa do direito. 4. ed. rev., atual. e ampl. São Paulo: Revista dos Tribunais, 2008.

SCOTT, Joan W. Gênero: uma categoria útil para análise histórica. Texto original: Gender a useful category of historical analyses. New York, Columbia University Press, 1989. Traduzido por: Christine Rufino Dabat e Maria Betânia Ávila.

SCOTT, Joan W. O enigma da igualdade. Rev. Estud. Fem., Florianópolis, v. 13, n. 1, abr. 2005. 
SERRANO, Rossana Maria Souto Maior. Conceitos de extensão universitária: um diálogo com Paulo Freire. Disponível em: <http://www.prac.ufpb.br/copac/extelar/atividades/discussao/artigos/conceitos_de_ext ensao_universitaria.pdf > Acesso em: 30 mar. 2015.

WAISELFISZ, Júlio Jacobo. Mapa da violência 2012. Atualização homicídios de mulheres no Brasil. Cebela/Flacso Brasil, 2012. Disponível em: <http://www.mapadaviolencia.org.br/pdf2012/MapaViolencia2012_atual_mulheres.pd f>. Acesso em: 18 fev. 2014. 